\title{
Synthesis of Some Bioactive Compounds and Its Application as Antimicrobial Agents for Plastic Industry
}

\author{
A.T. Zaitoun ${ }^{1}$, Yasser Assem ${ }^{2 *}$, Amany Arafa ${ }^{3}$, A.M. El-Masry ${ }^{4}$, S.A. Said ${ }^{4}$ \\ ${ }^{1}$ Research and Development Department, Egyptian Company for Plastic Industry \\ (Elsewedy-EgyPlast) $10^{\text {th }}$ of Ramadan City, Egypt. \\ ${ }^{2}$ Department of Polymers and Pigments, National Research Centre, 33 El Bohouth \\ St. (Former El Tahrir St.), Dokki, Giza, Cairo 12622, Egypt. \\ ${ }^{3}$ Department of Microbiology and Immunology, National Research Centre, $33 \mathrm{El}$ \\ Bohouth St. (Former El Tahrir St.), Dokki, Giza, Cairo 12622, Egypt. \\ ${ }^{4}$ Chemistry Department, Faculty of Science, Zagazig University, Zagazig, Egypt.
}

\begin{abstract}
JEW biocidal compounds were synthesized by reacting 4-hydroxy acetophenone with ethyl 1 cyanoacetate and 2-chlorobenzaldehydes and ammonium acetate in absolute ethanol to give 4-(2-chlorophenyl)-2-hydroxy-6-(4-hydroxyphenyl) nicotinonitrile which by epoxidation gives 4-(2-chlorophenyl)-6-(4-(oxiran-2-ylmethoxy) phenyl)-2-oxo-1,2-dihydropyridine-3carbonitrile. Another compound was synthesized by reacting 4-hydroxy acetophenone with ethyl cyanoacetate and 4-nitrobenzaldehydes and ammonium acetate in absolute ethanol to give 2-hydroxy-6-(4-hydroxyphenyl)-4-(4-nitrophenyl)nicotinonitrile witch by epoxidation gives 4-(4-nitrophenyl)-6-(4-(oxiran-2-ylmethoxy) phenyl)-2-oxo-1,2-dihydropyridine-3carbonitrile. The synthesized four compounds and standard biocide ( $\mathrm{Zn}$ omadine) were added separately to LDPE and HDPE and polystyrene in the same ratio ( $0.1 \mathrm{phr})$ followed by studying the melt flow rate and mechanical properties and electrical properties of LDPE and HDPE and polystyrene. In addition the biological activity of the prepared blends with LDPE or HDPE or PS were studied against two local isolates E. coli sero type O145 as gram-negative bacteria and S. epidermidis as gram-positive bacteria The antimicrobial test was performed quantitatively using the standard test method.
\end{abstract}

Keywords: 2-pyridone, epoxidation, antimicrobial activity, Plastic, Polyethylene, Polystyrene.

\section{Introduction}

Microbes are the source of infections [1]. The most cause of infectious diseases is the pathogenic microbes [2]. An antimicrobial agent is defined as a material used to kill or inhibit microbes. The antimicrobial agent in polymers include pyridine [3], imidazole [4], N-halamines [5], metal ions such as silver ions, copper ions, zinc ions [6-8], various types of quaternary ammonium [9-15] and phosphonium salts [16-20]. The antimicrobial polymers were discovered in 1965 [21]. The antimicrobial polymers are applied in the medical, food and textile industries.

According to the mechanism of antimicrobial activity, the activity of antimicrobial polymers can be categorized as either passive or active. A passive polymer layer can reduce protein adsorption on its surface, thereby preventing the adhesion of bacteria. Passive surfaces repel bacteria. Due to the mainly hydrophobic and negatively-charged properties of microbes, passive polymers should be either (1) hydrophilic; (2) negatively-charged; or (3) have a low surface free energy $[22,23]$. Active polymers actively kill bacteria that adhere to the polymer surface. Polymers functionalized with active actions can be classified as electrostatic interaction and biocidal interaction [24, 25].

Based on the polymer material type, antimicrobial polymers can be classified as bound or leaching antimicrobials. Antimicrobial polymers can be divided into three types: polymeric biocides, biocidal polymers, and biocide-releasing polymers [21]. Polymeric biocides are polymers that covalently link bioactive repeating units with 
antimicrobial activity such as amino, carboxyl, or hydroxyl groups [22, 26, 27]. Biocidal polymers contain cationic biocides, such as quaternary ammonium, phosphonium, tertiary sulfonium, and guanidinium. Microbes generally have a negative charge at the outer membrane of the cell. Cationic polymers can lead to the destabilization of the cell surface and the ultimate induction of bacterial death [28]. Biocide-releasing polymers can be realized by (1) polymerization of biocidereleasing molecules to polymeric backbone; or (2) polymer/biocide-releasing molecules composites. The polymer in biocide-releasing systems is used as a carrier for biocides. Polymers exhibit antibacterial properties through the incorporation of antibiotic and/or antiseptic compounds.

In this work, we focus our attention to synthesize two heterocyclic compounds of 2-pyridone derivatives and subjected them to alkylation with epichlorohydrin to give at the end four products. The action of these materials as antibacterial materials was examined as antibacterial additives in various plastics such as low density polyethylene (LDPE), high density polyethylene (HDPE) and polystyrene (PS). The effect of compounds on the main properties such as melt flow rate, mechanical properties and electrical properties of low LDPE, HDPE and PS was also investigated.

\section{Experimental}

\section{Materials}

Ammonium acetate, O-chlorobenzaldehyde, P-Nitrobenzaldehyde, Ethyl 2-cyanoacetate, P-Hydroxyacetophenone, all purchased from LOBA CHEMIE. Ethanol was purchased from ElNasr Pharmaceutical Chemicals Company, also Epichlorohydrinand N,N-dimethylformamide purchased from Merck, zinc pyrithione purchased from Arch Chemicals, polystyrene purchased from Pak Petrochemical Industries, High density polyethylene purchased from Sidpec, Low density polyethylene purchased from Versalis.

\section{Measurements and Instruments}

The plastic sheets were created using Labtech laboratory two-roll mill (LRM-SCR-150/0), Thailand.

The plastic plates and specimens for laboratory test were created using Gibitre laboratory press, Italy.

The melt flow rate was measured according to ASTM D 1238 using Zwick/Roel
plastometer(Mflow), Germany.

The mechanical properties (tensile strength and elongation at break) were measured according to BS EN 60811-1 using Gibitre Tensor Check, Italy.

Volume resistivity was measured according to ASTM D-275-99 using TOA Ultrameghometer (SM-8210), Japan.

Dielectric constant was measured according to ASTM D-669,ASTM D-150,UNI 4289 using Ceast instrument QMETER (mod. 0194C), Italy.

The ${ }^{1} \mathrm{H}$ NMR was measured using JEOL and BRUKER.NMR spectrometer in DMSO, and the chemical shift values were given in parts per million (ppm).Proton nuclear magnetic resonance ( ${ }^{1} \mathrm{H}$ NMR) was measured in deuterated water using Jeol ECA $500 \mathrm{MHz}$ NMR spectrometer.

All melting points are uncorrected and were measured using an Electro thermal IA 9100 apparatus.

General procedures for synthesis of 2-pyridone derivatives: $1 a \& b$

A mixture of 4-hydroxyphenone (10 mmol), ethyl cyanoacetate $(10 \mathrm{mmol})$, appropriate aldehydes namely 2-chlorobezaldehyde, 4-nitrobenzaldehyde $(10 \mathrm{mmol})$ and ammonium acetate $(80 \mathrm{mmol})$ in absolute ethanol $(20 \mathrm{ml})$ was heated under reflux for 12 hours [29,30]; the formed product was filtered off and recrystallized from acetic acid.

\section{Alkylation with epichlorohydrin}

A mixture of 1a,b (10 mmol), epichlorohydrin $(10 \mathrm{mmol})$ was added to dry DMF $(10 \mathrm{ml})$ in the presence of anhydrous $\mathrm{K}_{2} \mathrm{CO}_{3}(11 \mathrm{mmol})$, the reaction mixture was heated under reflux for 12 hours [31], cooled and poured onto ice water, the precipitate was collected, dry and recrystallization from methanol.

\section{Preparation of plastic sheets}

LDPE - blank was produced in sheet by rolling mill at $145{ }^{\circ} \mathrm{C} \&$ adding $\mathrm{Zn}$-omadine or $\mathrm{RA}_{1}$ or $\mathrm{RA}_{2}$ or $\mathrm{RC}_{1}$ or $\mathrm{RC}_{2}$ at $0.1 \%$ and mix again on the roll for (three: four) minutes followed by pressing $(1 \mathrm{~mm}$ thickness $)$ at $160{ }^{\circ} \mathrm{C}$ for three minutes. HDPE - blank and PS - plank was produced in sheet by rolling mill at $170{ }^{\circ} \mathrm{C}$ and adding $\mathrm{Zn}$ omadine or, $\mathrm{RA}_{1}$, or $\mathrm{RA}_{2}$, or $\mathrm{RC}_{1}$, or $\mathrm{RC}_{2}$ at 0.1 $\%$ and mix again on the roll for (three : four) minutes followed by pressing ( $1 \mathrm{~mm}$ thickness) at $175{ }^{\circ} \mathrm{C}$ for three minutes. Then the sheets were 
cooled at $23{ }^{\circ} \mathrm{C}$ for $16 \mathrm{hr}$, cutting the pressing sheet by dumbbell and testing the mechanical properties at speed $50 \mathrm{~mm} / \mathrm{min}$ and $23{ }^{\circ} \mathrm{C}$, cutting plastic sheet for $\left(10 \mathrm{~cm}^{*} 10 \mathrm{~cm}\right)$ and measuring volume resistivity, and cutting plastic sheet for $\left(12 \mathrm{~cm}^{*} 12 \mathrm{~cm}\right)$ and measuring dielectric constant.

Studying the biological activity of the prepared compounds

\section{Bacterial isolates}

Bacterial strains used in this study are local strains isolated and identified from normal water samples. The bacterial strains isolated from animal farms which isolated and identified according to [32] as follow: Under complete aseptic condition $1 \mathrm{ml}$ of water sample was added to $10 \mathrm{ml}$ peptone water and vigorously shaken then incubated for 8 to $12 \mathrm{~h}$ at $37^{\circ} \mathrm{C}$. Ten microliters of each sample were inoculated on mannitol salt agar plate and MacConkey agar plate then incubated at $37{ }^{\circ} \mathrm{C}$ for 18 to $24 \mathrm{~h}$. Identification of colonies isolated from mannitol salt agar plate was identified as staphylococci based on colony morphology, Gram staining, catalase reaction, oxidase test and oxidative-fermentative test. After the confirmation of the genus Staphylococcus, the enzyme coagulase was characterized using both the slide and tube methods. Coagulasenegative staphylococcus isolate was subjected to identification to the species level using the API Staph commercial identification system (API Staph bioMerieux ${ }^{\circledR}$ SA 69280 marcy1'Etoile/France) [33,34] which were identified as $S$. epidermidis. While colonies isolated from MacConkey agar plate were identified as E.coli based on colony morphology, Gram staining, oxidase test and tested by the indole, methyl red, Voges-Proskauer and Simmons citrate (IMVic) tests as putatively E. coli. The strains were subsequently characterized by the biochemical API 20E test system (Biomerieux) according to the manufacturer's instructions [35] and identified serologically as E. coli sero type O145. Strains identified were sub-cultured, Colonies were then transferred to Todd Hewitt broth (Becton Dickinson Diagnostic Systems, Sparks, MD), cultured at $37{ }^{\circ} \mathrm{C}$ for $18 \mathrm{~h}$ and stored in $20 \%$ glycerol solution at $-80{ }^{\circ} \mathrm{C}$ until its usage.

\section{Antibacterial test}

The antimicrobial activity of untreated and treated plastic sheets was tested against two isolates from animal farms(water samples) as $E$. coli sero type $O 145$ as gram-negative bacteria and $S$. epidermidis as gram-positive bacteria. The antimicrobial test was performed quantitatively using the standard test method according to the AATCC test method 100-1999 for Bacterial Counting [36]. All tests were conducted by standard plate count technique. All samples were prepared at a standered weight. Each microorganism used in this experiment were individually inoculated into tubes containing $5 \mathrm{~mL}$ BHI (brain heart infusion broth) sterile suspension. Such suspension was adjusted to 0.5 McFarland standards to match the turbidity of $1.5 \times 10-8 \mathrm{~mL}^{-1}$ colony forming unit (CFU)21. All samples were kept at controlled temperature of $37^{\circ} \mathrm{C}$. After incubation, transferred into $100 \mathrm{ml}$ of nutrient broth (1:500) and mix vigorously for 1 min. Ten fold dilution with $0.9 \%(\mathrm{w} / \mathrm{v})$ normal saline solution was prepared, spread at varying dilutions onto plates containing macConkey agar for $E$. coli and mannitol salt agar for $S$. epidermidis. Incubation to all plates was done at $37^{\circ} \mathrm{C}$ for $24 \mathrm{~h}$. All experiments were performed in triplicate. The antimicrobial activity is expressed in $\%$ reduction of the organisms after making contact with the test specimen compared to the number of the organism cells surviving after making contact with the control. All results were expressed according to the following equation:

$$
\text { Reduction }(\%)=\left(\frac{\mathrm{B}-\mathrm{A}}{\mathrm{B}}\right) \times 100
$$

Where $\mathrm{B}=$ the number of microorganisms present on untreated samples; and $\mathrm{A}=$ the number of microorganisms present on treated samples.

\section{Results and Discussion}

Synthesis and structural characterization

Two compounds of 2-pyridones derivatives were Synthesized and subjected to alkylation to give at the end 4 products. The structure of these four compounds was characterized by ${ }^{1} \mathrm{H}$ NMR.

Synthesis of 4-(2-chlorophenyl)-2-hydroxy-6(4-hydroxyphenyl) nicotinonitrile (RA1)

4-(2-chlorophenyl)-2-hydroxy-6-(4hydroxyphenyl) nicotinonitrile was synthesized by one-pot condensation. The synthesis process involves ethylcyanoacetate, 4-hydroxyacetophenone and 2-chlorobezaldehyde, in presence of ammonium acetate in refluxing ethanol (see Scheme 1).

A reasonable mechanism for this reaction is shown in Scheme 2, addition of compound (7) formed from para-hydroxyacetophenone and ammonium acetate adds to the compound (6) 
condensation product of 2-chlorobezaldehyde and

group followed by affords the desired product RA1.

ethylcynoacetate. Subsequent addition to a cyano

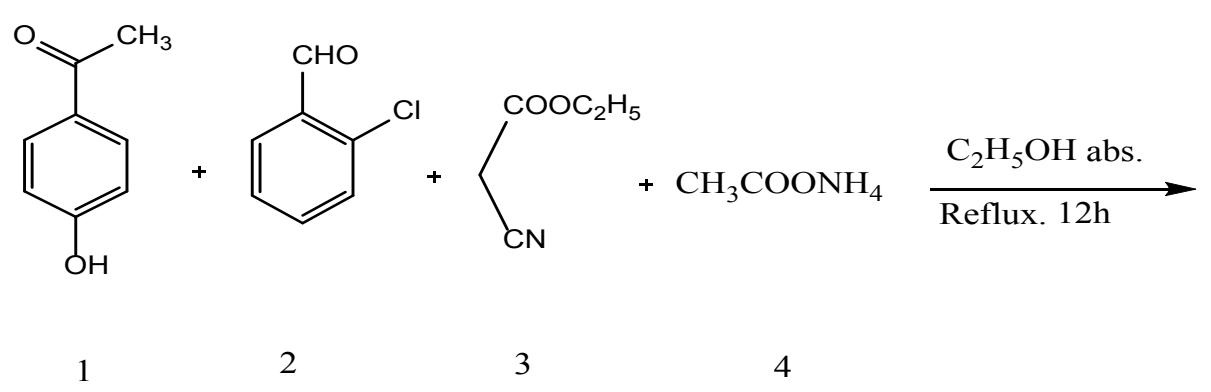

Scheme 1.<smiles></smiles>

(5) RA1

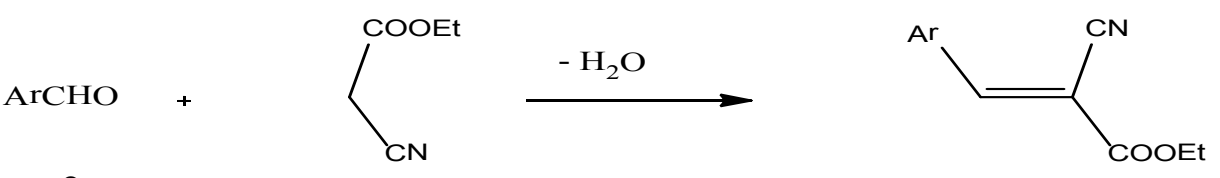

2<smiles>CC(=O)c1ccc(O)cc1</smiles>

1<smiles></smiles><smiles>C=C(N)c1ccc(O)cc1</smiles>

8

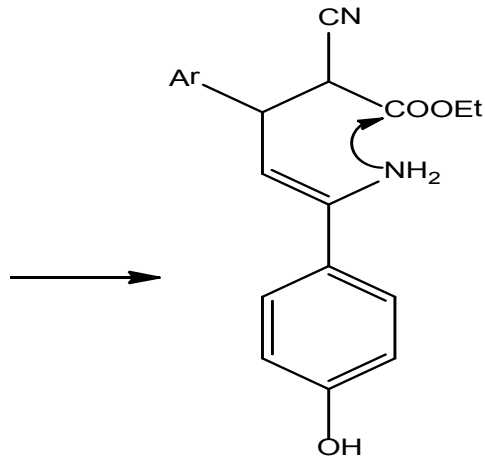<smiles>C=C(N)c1ccc(O)cc1</smiles>

7

RA1

Scheme 2. Mechanism of synthesis of 4-(2-chlorophenyl)-2-hydroxy-6-(4-hydroxyphenyl) nicotinonitrile. 
Synthesis of 4-(2-chlorophenyl)-6-(4-(oxiran-2ylmethoxy) phenyl)-2-oxo-1,2-dihydropyridine-3carbonitrile (RA2)

Epoxidation of 4-(2-chlorophenyl)-2hydroxy-6- (4-hydroxyphenyl) nicotinonitrile with epichlorohydrin in the presence of $\mathrm{K}_{2} \mathrm{CO}_{3}$ was achieved in dry DMF (See Scheme 3 ).
Synthesis of 2-hydroxy-6-(4-hydroxyphenyl)4-(4-nitrophenyl) nicotinonitrile (RC1)

2-hydroxy-6-(4-hydroxyphenyl)-4-(4nitrophenyl) nicotinonitrile was synthesized by one-pot condensation reaction. The synthesis process involves ethylcyanoacetate, 4-hydroxyacetophenone and 4-nitrobenzaldehyde,<smiles>N#Cc1c(-c2ccccc2Cl)cc(-c2ccc(O)cc2)nc1O</smiles>

RA 1

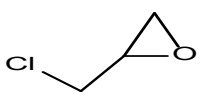<smiles></smiles>

Scheme 3. Synthesis of 4-(2-chlorophenyl)-6-(4-(oxiran-2-ylmethoxy) phenyl)-2-oxo-1,2-dihydropyridine-3-carbonitrile.<smiles>CCOC(=O)CCC#N</smiles><smiles>N#Cc1c(-c2ccc([N+](=O)[O-])cc2)cc(-c2ccc(O)cc2)n([TlH])c1=O</smiles>

Scheme 4. Synthesis of 2-hydroxy-6-(4-hydroxyphenyl)-4-(4-nitrophenyl) nicotinonitrile.

in presence of ammonium acetate in refluxing ethanol (see Scheme 4).

Synthesis of 4-(4-nitrophenyl)-6-(4(oxiran-2-ylmethoxy) phenyl)-2-oxo-1,2dihydropyridine-3-carbonitrile $(R C 2)$ :

Epoxidation of 2-hydroxy-6-(4-hydroxyphenyl)-4- (4-nitrophenyl) nicotinonitrile with epichlorohydrin in the presence of $\mathrm{K}_{2} \mathrm{CO}_{3}$ was performed in dry DMF (see Scheme 5).
Structural characterization

The structure of the prepared compounds was proven and characterized using ${ }^{1} \mathrm{H}$ NMR.

\section{Detailed NMR characterization}

Figure 1 shows the respective ${ }^{1} \mathrm{HNMR}$ of 4-(2-chlorophenyl)-2- hydroxy-6-(4hydroxyphenyl) nicotinonitrile. The nine aromatic protons $(1,2,5,6,9,15,16,18,19$, Fig. 1) appear at ppm (6.82-7.72), while the protons of hydroxyl group (20 Fig. 1) at ppm 3.9 and<smiles>N#Cc1c(-c2ccc([N+](=O)[O-])cc2)cc(-c2ccc(O)cc2)nc1O</smiles>

$\mathrm{RC} 1$<smiles>ClCC1CO1</smiles>

DMF

anhydrous $\mathrm{K}_{2} \mathrm{CO}_{3}$

Reflux. $12 \mathrm{~h}$<smiles>[R]C([R])=O</smiles>

Scheme 5. Synthesis of 4-(4-nitrophenyl)-6-(4-(oxiran-2-ylmethoxy) phenyl)-2-oxo-1,2-dihydropyridine-3-carbonitrile. 


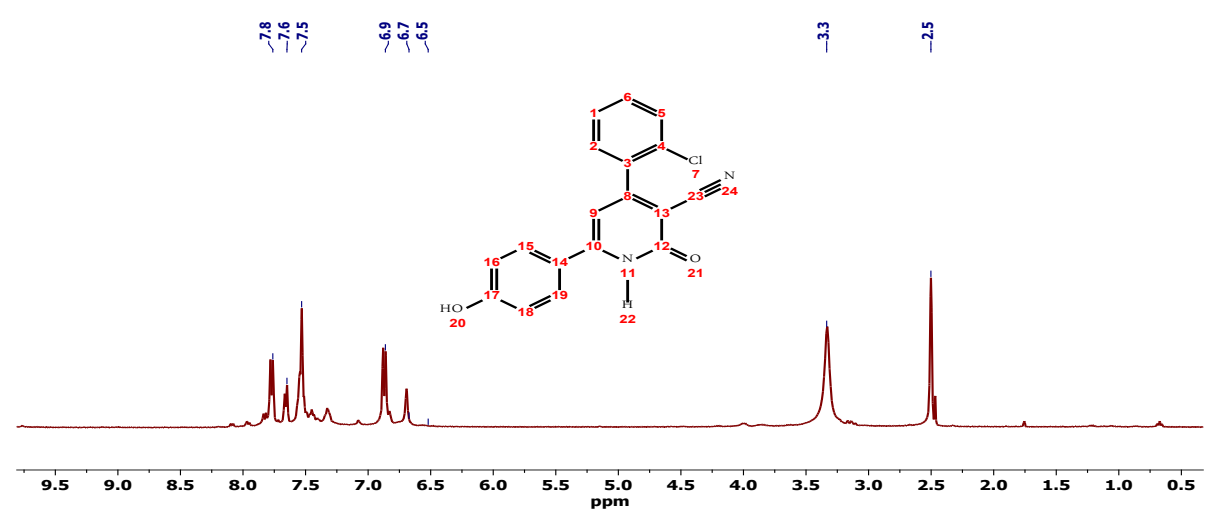

Fig. 1. ${ }^{1}$ HNMR spectrum of 4-(2-chlorophenyl)-2-hydroxy-6-(4-hydroxyphenyl) nicotinonitrile.

the proton of amine group (22 Fig. 1) at ppm 7.7 .

Figure 2 shows the respective ${ }^{1} \mathrm{HNMR}$ spectrum of 4-(2-chlorophenyl) -6-(4-(oxiran-2ylmethoxy) phenyl) -2-oxo-1,2-dihydropyridine-3carbonitrile. From ${ }^{1} \mathrm{H}-\mathrm{NMR}$ (Fig. 2), the following data was obtained, the three protons of oxiran ring of 4-(2-chlorophenyl)-6-(4-(oxiran-2-ylmethoxy) phenyl)-2-oxo-1,2-dihydropyridine-3-carbonitrile (23 1H, 25 2H, Fig. 2) appear at ppm 3.6, 3.8 ppm, the two protons $(222 \mathrm{H})$ appear at ppm 4.2, the nine aromatic protons $(1,2,5,6,9,15,16,18,199 \mathrm{H})$ appear at ppm (7.00-7.9) and the proton of amine group (6 Fig. 2) appear at ppm 10.1. It is also worth mention the disappearance of the proton $(\mathrm{OH})$ group (protons 1,6 at 10.26 ppm Fig. 1), a good sign for a successful epoxidation.

From ${ }^{1} \mathrm{H}-\mathrm{NMR}$ (Fig.3), the following data was obtained, the aromatic 4 protons $(1,2,4,5)$ of 2-hydroxy -6-(4-hydroxyphenyl) -4- (4-nitrophenyl) nicotinonitrile, appear at ppm 7.7, while the single proton (8 Fig. 3 ) appear at ppm 6.86, the four protons $(14,15,17,18)$ appear at ppm 7.5 and 7.01 , the proton of hydroxyl group (19 Fig. 3) at ppm 10.2 and the proton of amine group (21 Fig. 3) at ppm 12.48 .

From ${ }^{1} \mathrm{H}-\mathrm{NMR}$ (Fig. 4) the following data was obtained, the two protons of oxiran ring of 4-(4-nitrophenyl)-6-(4-(oxiran-2-ylmethoxy) phenyl)-2-oxo-1,2-dihydropyridine-3carbonitrile (1 Fig. 4) appear at ppm 2.46, the single proton of oxiran ring (2 Fig. 4) appear at ppm 3.99, the two protons (3 Fig. 4) appear at ppm 3.78 , the nine aromatic protons $(4,5,7,8,9$ Fig. 4) appear at ppm (7.02-7.9) and the proton of amine group (6 Fig. 4) appear at ppm 12.8 . It is also worth mention the disappearance of the proton $(\mathrm{OH})$ group (protons 6 at 10.2 ppm Fig. 3), a good sign for a successful epoxidation.

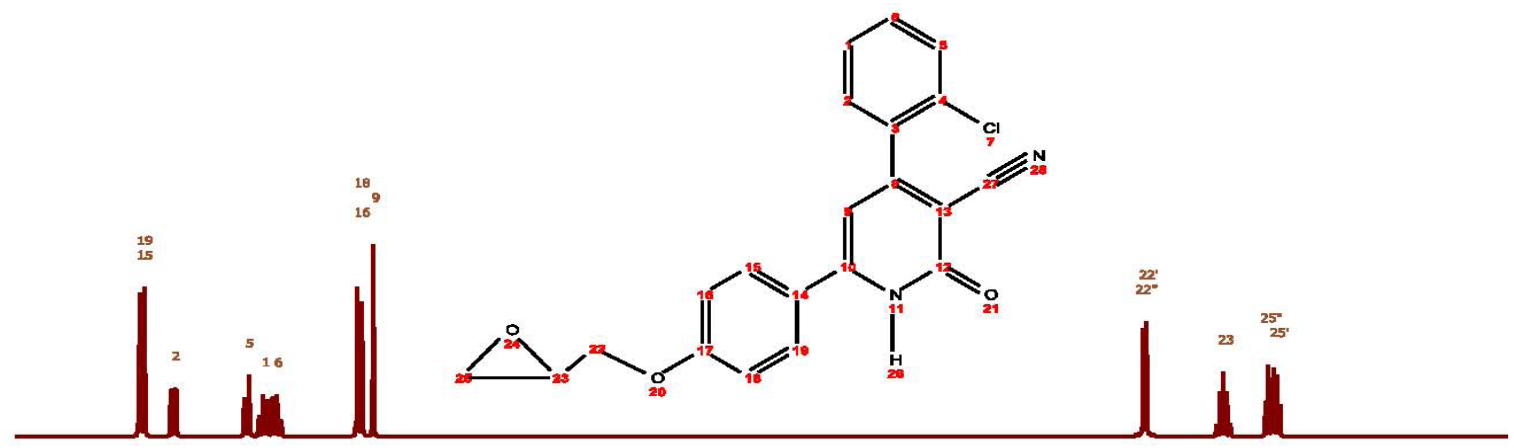

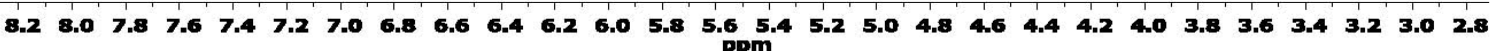

Fig. 2. ${ }^{1}$ H-NMR spectrum of 4-(2-chlorophenyl)-6-(4-(oxiran-2-ylmethoxy) phenyl)-2-oxo-1,2dihydropyridine-3-carbonitrile

Egypt. J. Chem. 61, No.3 (2018) 


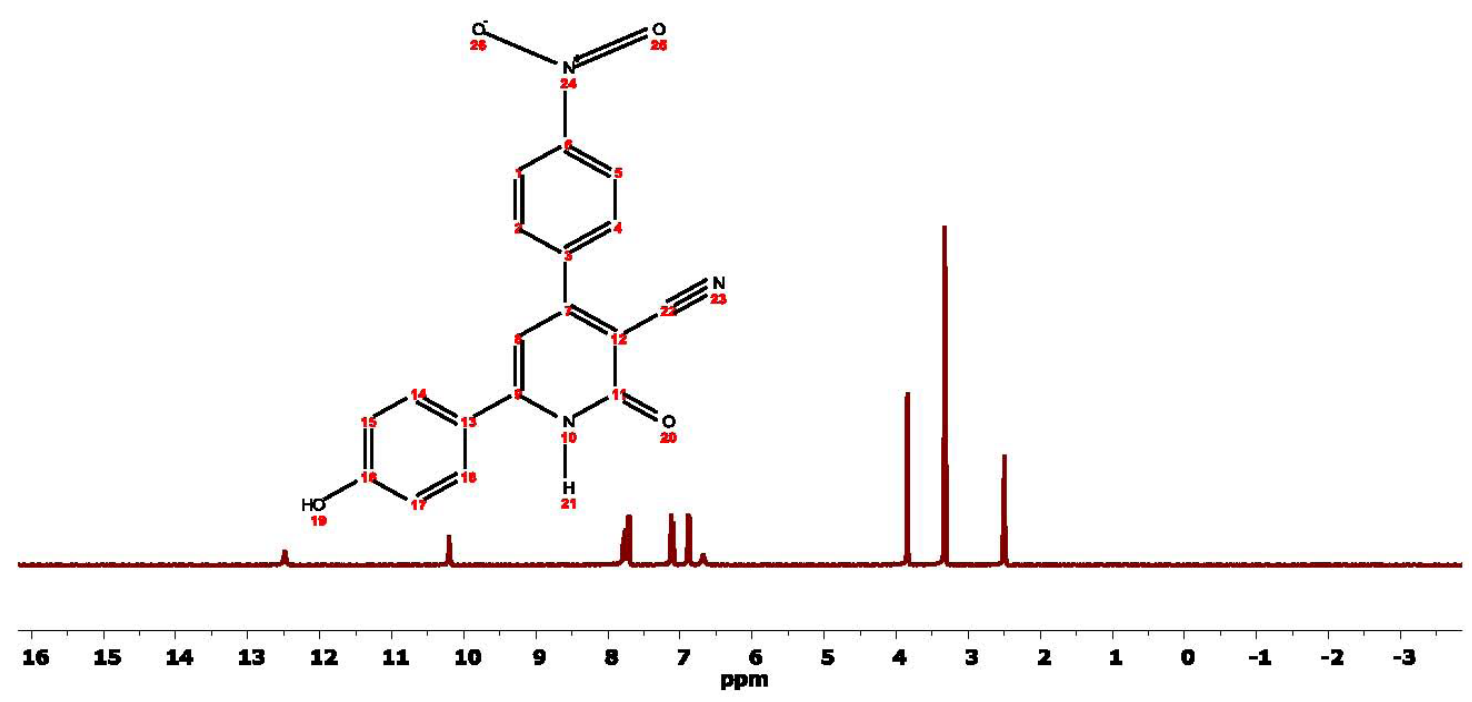

Fig. 3. ${ }^{1}$ H-NMR spectrum of 2-hydroxy-6-(4-hydroxyphenyl)-4-(4-nitrophenyl) nicotinonitrile.

Effect of the prepared compounds on the different plastic properties

The synthesized four compounds were used evaluated as antimicrobial agents and compared to the zinc pyrithione (standard antimicrobial additive) on different plastic sheets. The plastic used in this study are (LDPE, HDPE, and PS). The effect of these materials on the MFR, physical, mechanical and electrical properties of the forementioned plastics were investigated.

Effect of the prepared compounds on LDPE properties

In the following experiments the prepared compounds were added to LDPE. All of concentration $(0.1 \%)$. The effects of such addition on the MFR, physical, mechanical and electrical properties were studied.

The effect on melt flow rate of LDPE: At first the four compounds were mixed separately with four samples of the LDPE. The four samples were tested in a (plastometer) melt flow index instrument. The results of melt flow rate (MFR) are listed in Table 1 and represented graphically in Fig. 5. The values of MFR are mostly the same, and the adding of the prepared compounds to LDPE has no effect on the melt flow rate.
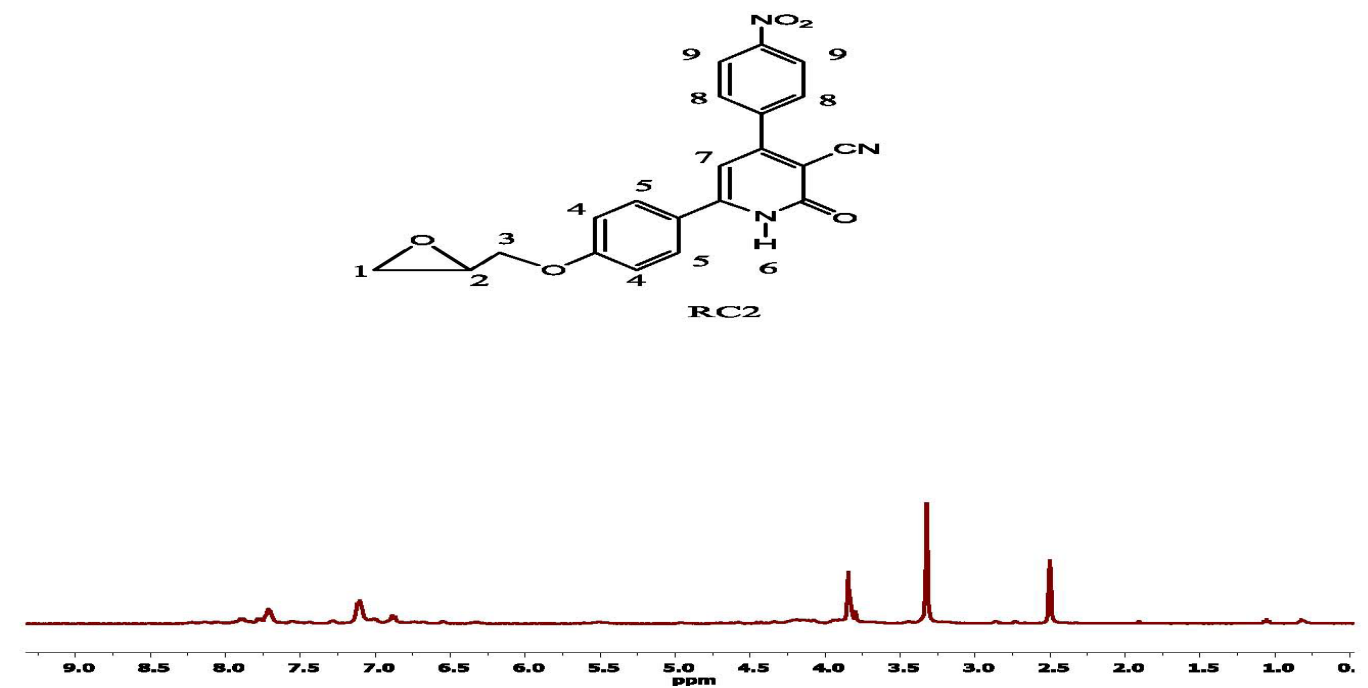

Fig.4. ${ }^{1}$ H-NMR spectrum of 4-(4-nitrophenyl)-6- (4-(oxiran-2-ylmethoxy) phenyl)-2-oxo-1,2dihydropyridine -3 -carbonitrile. 
TABLE 1. Change in MFR $\left(190{ }^{\circ} \mathrm{C}, 2.16 \mathrm{~kg}\right)$ with addition of the prepared compounds to LDPE.

\begin{tabular}{lcccccc}
\hline Specimen & LDPE & LD-0.1 Zn & LD-0.1 RA1 & LD-0.1 RA2 & LD-0.1 RC1 & LD-0.1 RC2 \\
\hline Symbol & LD-BLANK & LD-STD. & LD-RA1 & LD-RA2 & LD-RC1 & LD-RC2 \\
MFR(g/10min.) & 0.81 & 0.82 & 0.82 & 0.83 & 0.82 & 0.82 \\
\hline
\end{tabular}

The effect of the prepared compounds on mechanical properties of LDPE: Tensile strength and elongation at break of LDPE sheets was tested on a (tensor check) tensile machine according to ASTM D-638-03-2003. The test procedure was carried out at across head speed of $50 \mathrm{~mm} / \mathrm{min}$. and at room temperature conditions.

Tensile strength and elongation at break curves of LDPE/prepared compounds composites displayed that the adding of the prepared compounds to LDPE has a slight effect on the tensile strength properties, which is not significant. Also the elongation at break was not much affected. The blank sample was $910 \%$, while in all samples that contain the compounds the elongation was slightly decreased, that may be due to some physical interactions such as hydrogen bonding and/or surface migration. The results are shown in Fig.5 and 6.

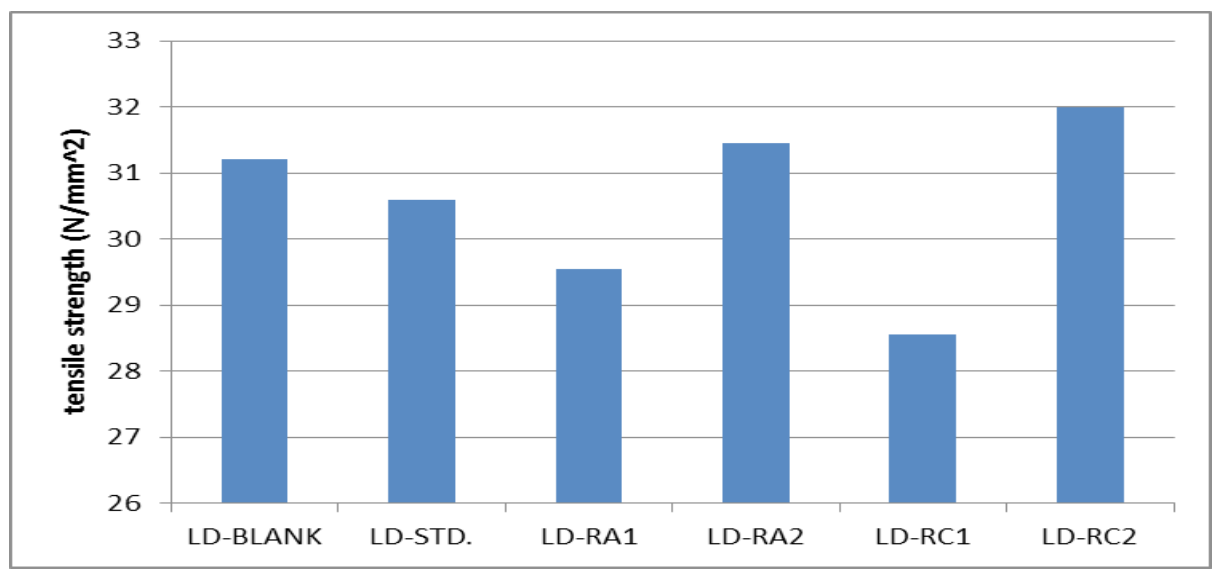

Fig. 5. Variation in tensile strength with addition of the prepared compounds to LDPE.

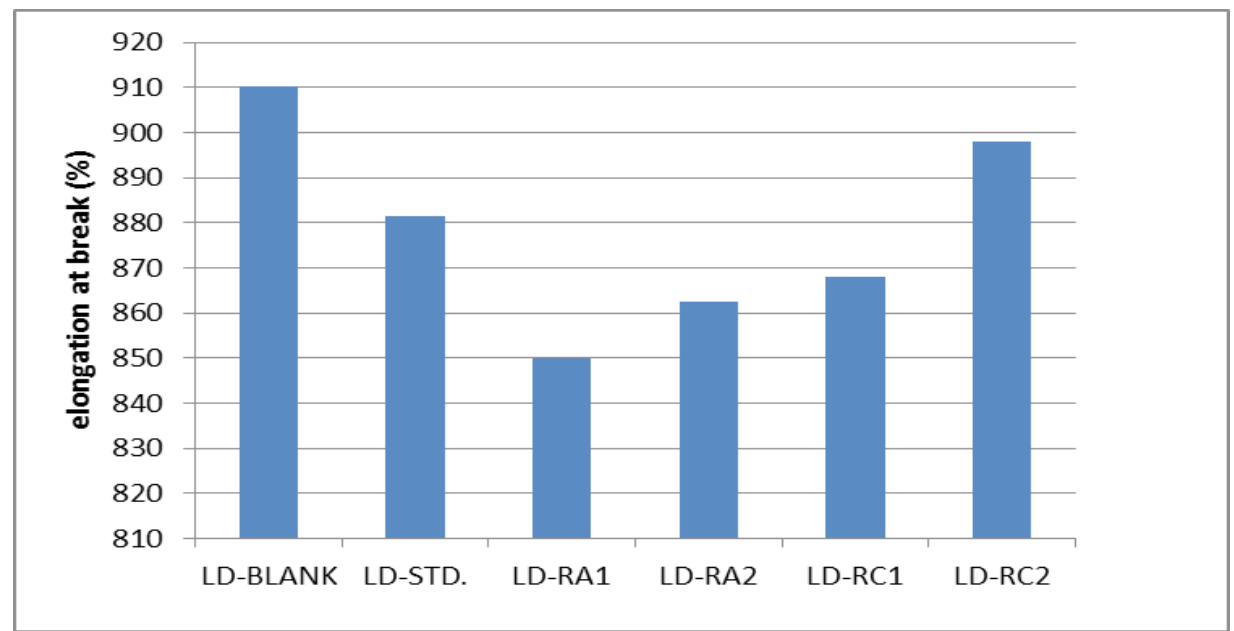

Fig.6. Variation in elongation at break with addition of the prepared compounds to LDPE. 
Effect of addition of the prepared compounds on electrical properties of LDPE

Effect of the prepared compounds on volume resistivity of $L D P E$

Volume resistivity is the electrical resistance through a cube of an insulating material. When expressed in ohm-centimeters, it would be the electrical resistance through a onecentimeter cube of insulating material. The Volume resistivity was determined using (TOA Ultrameghometer) according to ASTM D-275-99. LDPE is covalently bonded; they are, in principle, electrical insulators, due to an absence of free and mobile electrons or ions. By measuring the volume resistivity of the prepared LDPE samples, it was found that the volume resistivity multiplied by three after adding $\mathrm{RC} 2$. It can be expected that the addition of RC2 which have a low polarity will have a low melting point as a compound with a low polarity will have a weak dipole-dipole bond and will require a low energy to break that bond. The existence of polarity or double bonds reduces resistivity so RC2 with a low polarity improve the volume resistivity [37]. It was found that the volume resistivity of RA2 and RC2 is higher than $\mathrm{RA} 1$ and $\mathrm{RC} 1$ in the order, it can be expected that the epoxidation of RA1 and $\mathrm{RC} 1$ causes a decrease in polarity and melting point followed by increasing in volume resistivity of RA1 and RC1. On the other hand, it was found that the volume resistivity decrease after adding zinc pyrithione. It can be expected that zinc pyrithione having four co-ordinate bonds and this cause increasing in polarity and decreasing in volume resistivity. The effect of adding the prepared compounds to LDPE on its volume resistivity was shown in Table 2.

TABLE 2. Change in volume resistivity with addition of the prepared compounds to LDPE.

\begin{tabular}{lcccccc}
\hline Specimen & LDPE & LD-0.1 Zn & LD-0.1 RA1 & LD-0.1 RA2 & LD-0.1 RC1 & LD-0.1 RC2 \\
\hline $\begin{array}{l}\text { Symbol } \\
\begin{array}{l}\text { Volume resistivity } \\
\text { (ohm.cm) }\end{array}\end{array}$ & LD-BLANK & LD-STD. & LD-RA1 & LD-RA2 & LD-RC1 & LD-RC2 \\
\hline
\end{tabular}

The effect of addition of the prepared compounds on dielectric constant of $L D P E$

The effect of adding the prepared compounds to LDPE on its dielectric constant was shown in Fig.7.

Effect of the prepared compounds to HDPE properties

The same evaluation steps were followed exactly when HDPE was used as the parent matrix.

The effect on melt flow rate of HDPE

At first a HDPE sheet was prepared by roll mill and the four compounds were mixed separately with four samples of the LDPE. The four samples were tested in a (plastometer) melt flow index instrument. The results of melt flow rate (MFR) are listed in Table 3. The values of MFR are mostly the same, and the melt behavior is mostly unchanged.

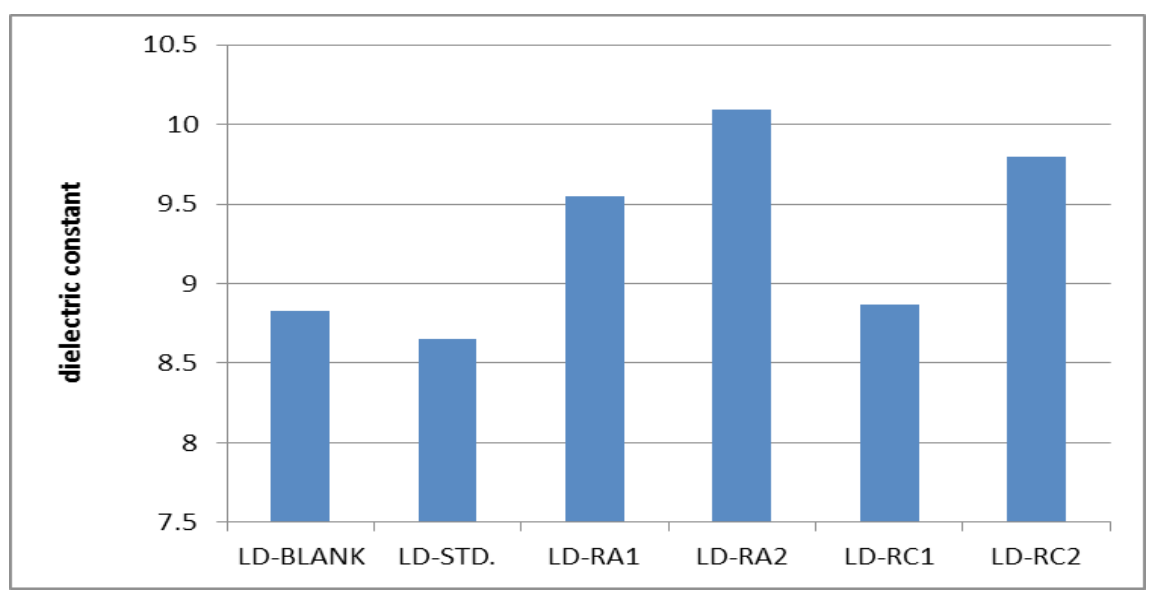

Fig. 7.Variation in dielectric constant at break with addition of the prepared compounds to LDPE. 
TABLE 3. Change in MFR $\left(190^{\circ} \mathrm{c}, 2.16 \mathrm{~kg}\right)$ with addition of the prepared compounds to HDPE.

\begin{tabular}{lcccccc}
\hline Specimen & HDPE & HD-0.1 Zn & HD-0.1 RA1 & HD-0.1 RA2 & HD-0.1 RC1 & HD-0.1 RC2 \\
\hline Symbol & HD-BLANK & HD-STD. & HD-RA1 & HD-RA2 & HD-RC1 & HD-RC2 \\
MFR(g/10min.) & 0.19 & 0.2 & 0.2 & 0.21 & 0.21 & 0.2 \\
\hline
\end{tabular}

The effect of the prepared compounds on mechanical properties of HDPE

Tensile strength and elongation at break of HDPE sheets was tested on a (tensor check) tensile machine according to ASTM D-63803-2003. The test procedure was carried out at across head speed of $50 \mathrm{~mm} / \mathrm{min}$. and at room temperature conditions.
Tensile strength and elongation at break curves of HDPE/prepared compounds composites displayed that the adding of the prepared compounds to HDPE has a slight effect on the tensile strength properties, which is not significant. Also the elongation at break was not much affected. The results are shown in Fig.8 and 9 .

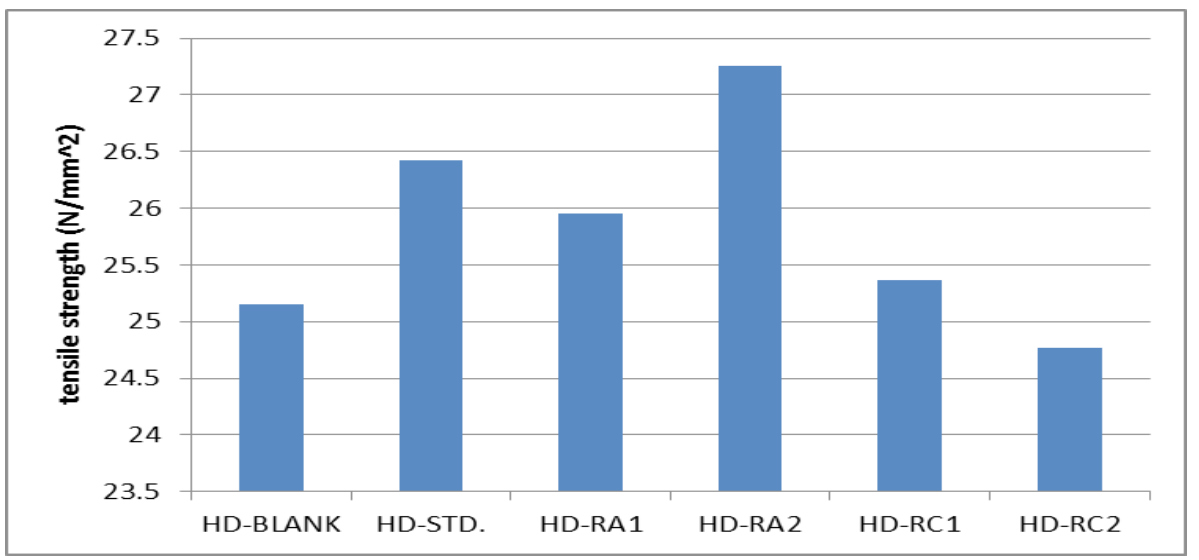

Fig. 8. Variation in tensile strength with addition of the prepared compounds to HDPE.

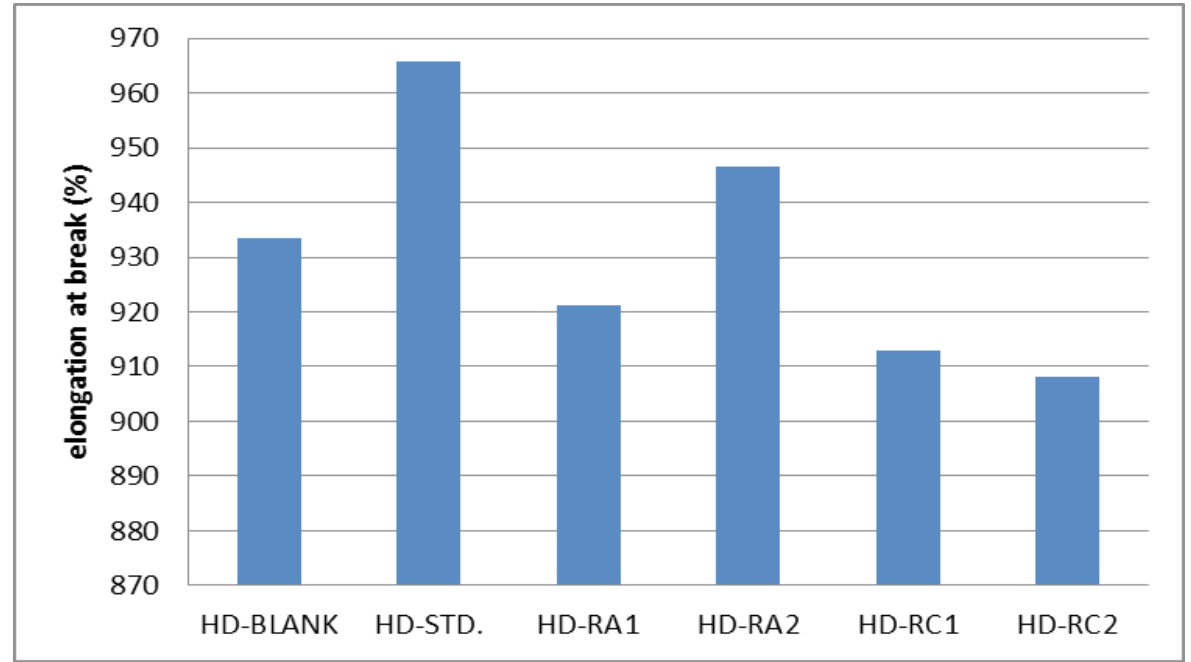

Fig. 9. Variation in elongation at break with addition of the prepared compounds to HDPE.

Egypt. J. Chem. 61, No.3 (2018) 
Effect of addition of the prepared compounds on electrical properties of HDPE

The effect of the prepared compounds on volume resistivity of $H D P E$

HDPE is covalently bonded; they are, in principle, electrical insulators, due to an absence of free and mobile electrons or ions. The Volume resistivity was determined using (TOA Ultrameghometer) according to ASTM D-275-99. By measuring the volume resistivity of the prepared HDPE sheets, it was found that the volume resistivity multiplied by three after adding RC2. It can be expected that the addition of $\mathrm{RC} 2$ which have a low polarity will have a low melting point and improve the volume resistivity. It was found that the volume resistivity of RA2 and $\mathrm{RC} 2$ is higher than RA1 and RC1 in the order, it can be expected that the epoxidation of RA1 and RC1 causes a decrease in polarity and melting point followed by increasing in volume resistivity of RA1 and RC1. On the other hand, it was found that the volume resistivity decrease after adding zinc pyrithione. It can be expected that zinc pyrithione having four co-ordinate bonds and this cause increasing in polarity and decreasing in volume resistivity. The effect of adding the prepared compounds to HDPE on its volume resistivity was shown in Table 4.

TABLE 4. Change in volume resistivity with addition of the prepared compounds to HDPE.

\begin{tabular}{lcccccc}
\hline Specimen & HDPE & HD-0.1 Zn & HD-0.1 RA1 & HD-0.1 RA2 & $\begin{array}{c}\text { HD-0.1 } \\
\text { RC1 }\end{array}$ & HD-0.1 RC2 \\
\hline symbol & $\begin{array}{c}\text { HD- } \\
\text { BLANK }\end{array}$ & HD-STD. & HD-RA1 & HD-RA2 & HD-RC1 & HD-RC2 \\
$\begin{array}{l}\text { volume resistivity } \\
\text { (ohm.cm) }\end{array}$ & $6.2^{*} 10^{\wedge} 16$ & $4 * 10^{\wedge} 16$ & $11.3^{*} 10^{\wedge} 16$ & $12.3^{*} 10^{\wedge} 16$ & $11.9^{*} 10^{\wedge} 16$ & $13.7^{*} 10^{\wedge} 16$ \\
\hline
\end{tabular}

The effect of addition of the prepared compounds on dielectric constant of HDPE

Effect of adding the prepared compounds to HDPE on its dielectric constant was shown in Table 5.

Effect of the prepared compounds to PS properties

In the following experiments the prepared compounds were added to PS. All of concentration $(0.1 \%)$. The effects of such addition on the MFR, physical, mechanical and electrical properties were studied.

\section{The effect on melt flow rate of $P S$}

A PS sheet was prepared by roll mill and the four compounds were mixed separately with four samples of the LDPE. The four samples were tested in a (plastometer) melt flow index instrument. The results of melt flow rate (MFR) are listed in Table 6 . The values of MFR of the prepared polystyrene samples, it was found that the melt flow rate increased about $30 \%$ after adding RC2. It can be expected that RC2 has the lowest melt point, and because of its dispersion in the PS sheet, it may penetrate the PS polymeric chain and, helps in fast flow of PS sample.

TABLE 5. Change in dielectric constant with addition of the prepared compounds to HDPE.

\begin{tabular}{lcccccc}
\hline Specimen & HDPE & HD-0.1 Zn & HD-0.1 RA1 & HD-0.1 RA2 & HD-0.1 RC1 & HD-0.1 RC2 \\
\hline Symbol & HD-BLANK & HD-STD. & HD-RA1 & HD-RA2 & HD-RC1 & HD-RC2 \\
Dielectric constant & 8.63 & 8.59 & 9.46 & 9.37 & 8.99 & 9.55 \\
\hline
\end{tabular}

TABLE 6. change in MFR $\left(200^{\circ} \mathrm{c}, 5 \mathrm{~kg}\right)$ with addition of the prepared compounds to PS.

\begin{tabular}{lcccccc}
\hline Specimen & PS & PS-0.1 Zn & PS-0.1 RA1 & PS-0.1 RA2 & PS-0.1 RC1 & PS-0.1 RC2 \\
\hline Symbol & PS-BLANK & PS-STD. & PS-RA1 & PS-RA2 & PS-RC1 & PS-RC2 \\
MFR(g/10min.) & 10.36 & 9.5 & 9.47 & 10.1 & 10.02 & 13.79 \\
\hline
\end{tabular}


The effect of the prepared compounds on mechanical properties of PS

Tensile strength and elongation at break of PS sheets was tested on a (tensor check) tensile machine according to ASTM D-638-03-2003. The test procedure was carried out at across head speed of $50 \mathrm{~mm} / \mathrm{min}$. and at room temperature conditions.

TABLE 7. Change in tensile strength with addition of the prepared compounds to PS.

\begin{tabular}{|l|c|c|c|c|c|c|}
\hline Specimen & PS & PS-0.1 Zn & PS-0.1 RA1 & PS-0.1 RA2 & PS-0.1 RC1 & PS-0.1 RC2 \\
\hline Symbol & PS-BLANK & PS-STD. & PS-RA1 & PS-RA2 & PS-RC1 & PS-RC2 \\
\hline $\begin{array}{l}\text { Tensile } \\
\text { strength (N/ } \\
\text { mm^2) }\end{array}$ & 25.14 & 20.37 & 19.63 & 21.43 & 24.85 & 21.61 \\
\hline $\begin{array}{l}\text { Elongation } \\
\text { at break (\%) }\end{array}$ & 1.78 & 1.57 & 1.45 & 1.75 & 2.4 & 1.31 \\
\hline
\end{tabular}

Effect of addition of the prepared compounds on electrical properties of PS

Effect of the prepared compounds on volume resistivity of $P S$

Polystyrene is covalently bonded; they are, in principle, electrical insulators, due to an absence of free and mobile electrons or ions. The Volume resistivity was determined using (TOA Ultrameghometer) in according to ASTM D-275-99. By measuring the volume resistivity of the prepared polystyrene sheets, it was found that the volume resistivity multiplied by three after adding RC2. It can be expected that the addition of RC2 which have a low polarity will improve the volume resistivity. It was found that the volume resistivity of RA2 and RC2 is higher
Tensile strength and elongation at break curves of PS/prepared compounds composites displayed that the adding of the prepared compounds to polystyrene has a slight effect on the tensile strength properties, which is not significant. Also the elongation at break was not much affected. The results are shown in Table 7.

TABLE 8. Change in volume resistivity with addition of the prepared compounds to PS.

\begin{tabular}{lcccccc}
\hline Specimen & PS & PS-0.1 Zn & PS-0.1 RA1 & PS-0.1 RA2 & PS-0.1 RC1 & PS-0.1 RC2 \\
\hline $\begin{array}{l}\text { Symbol } \\
\begin{array}{l}\text { Volume resistivity } \\
\text { (ohm.cm) }\end{array}\end{array}$ & PS-BLANK & PS-STD. & PS-RA1 & PS-RA2 & PS-RC1 & PS-RC2 \\
\hline
\end{tabular}

TABLE 9. change in dielectric constant with addition of the prepared compounds to PS.

\begin{tabular}{lcccccc}
\hline Specimen & PS & PS-0.1 Zn & PS-0.1 RA1 & PS-0.1 RA2 & PS-0.1 RC1 & PS-0.1 RC2 \\
\hline Symbol & PS-BLANK & PS-STD. & PS-RA1 & PS-RA2 & PS-RC1 & PS-RC2 \\
$\begin{array}{l}\text { Dielectric } \\
\text { constant }\end{array}$ & 7.78 & 6.77 & 9.37 & 8.86 & 8.51 & 10.09 \\
\hline
\end{tabular}


The effect of addition of the prepared compounds on Antibacterial properties of plastic

The development of antimicrobial additives for plastic is an important purpose for their application in many fields. The antimicrobial activities of blank and the prepared compounds incorporated plastic against local bacterial strains recovered from normal water samples (Staphylococcusepidermidis and Escherichia coli 0145 ) were evaluated by using the plate agar count method. As depicted in Table 10, it is clear that the highest reduction percent against Staphylococcus epidermidis and Escherichia coli O145 was in PS-RC1 sample.

The antibacterial rate against $S$. epidermidiswas $100 \%$ in sample number 3 and 4 then decreased to $98.5 \%, 92.8 \%, 91.4 \%, 58.6 \%$, $35 \%$ and 22.5 while. The antibacterial rate against E.coli was71.1\%, $67.3 \%$, $67.16 \%, 54.8 \%, 63.4 \%, 62.6 \%, 40.2 \%$ and $34.6 \%$.

TABLE 10. Showing the percentage of the bacterial growth reduction

\begin{tabular}{cccc}
\hline Sample number & Sample code & $\begin{array}{c}\text { Reduction \% against } \\
\text { S. epidermidis }\end{array}$ & $\begin{array}{c}\text { Reduction \% against } \\
\text { E.coli }\end{array}$ \\
\hline 1 & HD-RA1 & 35 & 40.2 \\
\hline 2 & HD-RA2 & 22.5 & 63.4 \\
\hline 3 & HD-RC1 & 100 & 62.6 \\
\hline 4 & HD-RC2 & 100 & 67.16 \\
\hline 5 & PS-RA1 & 58.6 & 54.8 \\
\hline 6 & PS-RA2 & 92.8 & 34.6 \\
\hline 7 & PS-RC1 & 98.5 & 71.1 \\
\hline 8 & PS-RC2 & 91.4 & 67.3 \\
\hline
\end{tabular}

Reduction \% is the percent of reducing bacterial growth.

\section{Conclusion}

Some biocidal compounds were synthesized by the following reaction:

Reaction between 4-hydroxyacetophenone, ethyl cyanoacetate, 2-chlorobenzaldehydes, and ammonium acetate in absolute ethanol as a solvent was heated under reflux for 12 hours which give a new compound known as 4-(2-chlorophenyl)2-hydroxy-6-(4-hydroxyphenyl) nicotinonitrile which by epoxidation give 4-(2-chlorophenyl)6-(4-(oxiran-2-ylmethoxy) phenyl)-2-oxo-1,2dihydropyridine-3-carbonitrile.

Another reaction was done between 4-hydroxyacetophenone, ethyl cyanoacetate, 4-nitrobenzaldehydes, and ammonium acetate in absolute ethanol as a solvent was heated under reflux for 12 hours which give anew compound known as 2-hydroxy-6-(4-hydroxyphenyl)-4-(4nitrophenyl)nicotinonitrile which by epoxidation give 4-(4-nitrophenyl) -6-(4- (oxiran-2ylmethoxy) phenyl) -2-oxo-1,2- dihydropyridine3-carbonitrile.

The synthesized four compounds and zinc pyrithione (standard biocide) were added separately by one ratio $(0.1 \%)$ to LDPE or HDPE or PS then the melt flow was studied and it was found that the addition of five compounds to LDPE or HDPE have no effect. On the other hand, the addition of five compounds to PS have observed effect on its MFR and it was found the addition of RC2 which have the least melting point, has the highest MFR.

The mechanical properties of the prepared blends with LDPE or HDPE or PS were studied and it was found that the addition of five compounds to LDPE or HDPE or PS make a slight effect on its tensile strength and elongation at a break.

The volume resistivity of the prepared blends with LDPE or HDPE or PS were studied and it was found that the addition of five compounds to LDPE or HDPE or PS have an effect on its volume resistivity and it was noticed that the addition of a compound which has little polarity improve the volume resistivity and the addition of a compound which has a high polarity decrease the volume resistivity.

The biological activity of the prepared blends with HDPE or PS were studied against Gram positive and Gram negative bacteria using the plate agar count method and it was found that all of the prepared blends with HDPE or PS have anti-bacterial activity against Staphylococcus 
epidermidis and Escherichia coli O145 and PS-RC1 sample have the highest anti-bacterial activity.

\section{References}

1. Ross, A.G.P.; Olds, G.R.; Cripps, A.W.; Farrar, J.J. and McManus, D.P. Enteropathogens and chronic illness inreturning travelers. N. Engl. J. Med., 368, p.1817-1825 (2013).

2. Lin, Y.S.; Lee, M.Y.; Yang, C.H. and Huang, K.S. Biomedical devices for pathogen detection using microfluidic chips. Curr. Proteom., 11, 116-120 (2014).

3. Sadana, A.K.; Mirza, Y.; Aneja, K.R. and Prakash, O., Eur.J. Med. Chem., 38, 533 (2003).

4. Khabnadideh, S.; Rezaei, Z.; Khalafi-Nezhad, A.; Bahrinajafi, R.; Mohamadi, R. and Farrokhroz, A.A. Bioorg. Med. Chem. Lett., 13, 2863 (2003).

5. Chen, Y. and Han, Q. X., Appl. Surf. Sci., 257, 6034 (2011).

6. Raghavendra, G.M.; Jayaramudu, T.; Varaprasad, K.; Sadiku, R.; Ray, S.S. and Raju, K. M., Carbohyd. Polym., 93, 553 (2013).

7. Ren, G.G.; Hu, D.W.; Cheng, E.W.C.; Vargas-Reus, M.A.; Reip, P. and Allaker, R.P., Int. J. Antimicrob. Ag., 33, 587 (2009).

8. Rajendra, R.; Balakumar, C.; Ahammed, H.A.M.; Jayakumar, S.; Vaideki, K. and Rajesh, E., Int. J. Eng. Sci. Technol., 2, 202 (2010).

9. Jiang, S.; Wang, L.; Yu, H.J. and Chen, Y. React. Funct. Polym., 62, 209 (2005).

10. Dizman, B.; Elasri, M.O. and Mathias, L.J., J. Polym. Sci.Pol. Chem., 44, 5965 (2006).

11. Harney, M.B.; Pant, R.R.; Fulmer, P.A. and Wynne, J.H., Appl. Mater. Interfaces, 1, 39 (2008).

12. Waschinski, C.J.; Zimmermann, J.; Salz, U.; Hutzler, R.; Sadowski, G. and Tiller, J.C. $A d v$. Mater., 20, 104 (2008).

13. Kim, C.H.; Choi, J.W.; Chun, H.J. and Choi, K.S., Polym. Bull., 38, 387 (1997).

14. Huang, J.Y.; Koepsel, R.R.; Murata, H.; Wu, W.; Lee, S.B.; Kowalewski, T.; Russell, A.J. and Matyjaszewski, K., Langmuir., 24, 6785 (2008).

15. Sauvet, G.; Fortuniak, W.; Kazmierski, K. and Chojnowski, J., J. Polym. Sci. Pol. Chem., 41, 2939 (2003).

Egypt. J. Chem. 61, No.3 (2018)
16. Kenawy, E.R.; Abdel-Hay, F.I.; El-Magd, A.A. and Mahmoud, Y., React. Funct.Polym., 66, 419 (2006).

17. Kenawy, E.R.; Abdel-Hay, F.I.; El-Shanshoury, A.E.R. and El-Newehy, M.H., J. Polym. Sci. Pol. Chem., 40, 2384 (2002).

18. Kanazawa, A.; Ikeda, T. and Endo, T., J. Polym. Sci. Pol.Chem., 31, 3003 (1993).

19. Kanazawa, A.; Ikeda, T. and Endo, T., J. Appl. Polym. Sci., 52, 641 (1994).

20. Kanazawa, A.; Ikeda, T. and Endo, T., J. Appl. Polym. Sci., 28, 1305 (1994).

21. Siedenbiedel, F. and Tiller, J.C., Antimicrobial polymers in solution and on surfaces: Overview and functional principles. Polymers, 4, 46-71 (2012).

22. Francolini, I.; Donelli, G.; Crisante, F.; Taresco, V. and Piozzi, A., Antimicrobial polymers for anti-biofilm medical devices: State-of-art and perspectives. Adv. Exp. Med. Biol., 831, 93-117 (2015).

23. Zhang, H. and Chiao, M., Anti-fouling coatings of poly(dimethylsiloxane) devices for biological and biomedical applications. J. Med. Biol. Eng., 35, 143-155 (2015).

24. Xue, Y.; Xiao, H. and Zhang, Y., Antimicrobial polymeric materials with quaternary ammonium and phosphonium salts. Int. J. Mol. Sci., 16, 36263655 (2015).

25. Jain, A.; Duvvuri, L.S.; Farah, S.; Beyth, N.; Domb, A.J. and Khan, W., Antimicrobial polymers. $A d v$. Healthc. Mater., 3, 1969-1985 (2014).

26. Sedlarik, V., Antimicrobial modifications of polymers. In Biodegradation-Life of Science; Chamy, R.,Rosenkranz, F., Eds.; InTech: Rijeka, Croatia, p.187-204 (2013).

27. Martins, A.F.; Facchi, S.P.; Follmann, H.D.; Pereira, A.G.; Rubira, A.F. and Muniz, E.C., Antimicrobial activity of chitosan derivatives containing n-quaternized moieties in its backbone: A review. Int. J. Mol. Sci., 15, 20800-20832 (2014).

28. Deka, S.R.; Sharma, A.K. and Kumar, P. Cationic polymers and their self-assembly for antibacterial applications. Curr. Top. Med. Chem., 15, p.11791195 (2015).

29. Mohamed S.F.; Youssef M.M.; Amr A.E.; Kotb E.R., Sci. Pharm., 76, 279-303 (2008).

30. Abadi A.H.; Abouel-Ella D.A.; Lehman J.; 
Tinsley H.N.; Gary B.D.; Piazza G.A.; Abdel-Fattah M.A.O., Eur. J. Med. Chem. 45, 90-97 (2010).

31. Haggam R. A.; El-Sayed H. A.; Said S. A.; Ahmed M. H. M.; Moustafa A. H.; Abd-El-Noor R. E., O-Glycosylation/Alkylation and Antimicrobial Activity of 4,6-Diaryl-2-Oxonicotinonitrile Derivatives, J. Heterocyclic Chemistry, 54, 375383 (2017).

32. Quinn, P.J.; Markey, B.K.; Leonard, F.C.; FitzPatrick, E.S.; Fanning, S. and Hartigan P.J.,Veterinary Microbiology and Microbial Diseases. Second. WILEY-BLACKWELL.A John Wiley \& Sons, Ltd., Publication (2011).

33. Arafa, A.A.; Ibrahim, E.S.; Fouad, E.A. and Gaber, E.S., Antibiotic Resistance of Staphylococci Concerning Strains Included in Food Industry in Egypt. International Journal of Pharmaceutical and Clinical Research, 8 (12), 1583-1589 (2016).
34. Thorberg, B.M.; Kühn, I; Aarestrup, F.M.; Brändström, B.; Jonsson, P. and Danielsson-Tham, M.L., Pheno- and genotyping of Staphylococcus epidermidis isolated from bovine milk and human skin. Vet Microbiol, 115, 163-172 (2006).

35. Osman, K.M.; El-Hariri, M.D. and Abd-El-Hamed, G.S., Mass gatherings pose a threat to the spread of antimicrobial resistant E. coli strains. International Journal of Advanced Research, 2(4), 592-601 (2014).

36. Rehan, M.; Mashaly, H.M.; Mowafi, S.; El-Kheir, A.A. and Emam, H.E., Multi-functional textile design using in-situ Ag NPs incorporation into natural fabric matrix. Dyes Pigment, 118, 9-17 (2015).

37. Ram, A., Fundamentals of Polymer Engineering, 4, 90 (1997).

(Received 18/2/2018; accepted $12 / 4 / 2018$ )

\section{تخليق بعض المركبات ذات النشاط ت الحيوي و تطبيقاتها كعوامل مضادة للميكروبات في صناعة البلاستيك بـن

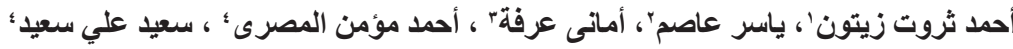

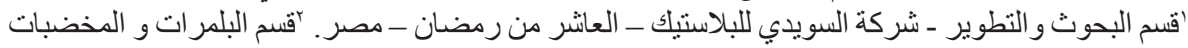

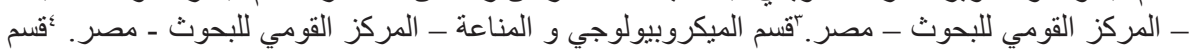

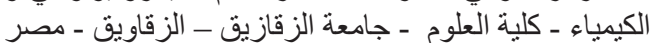

تم تخليق بعض المركبات ذات ابادة حيوية بواسطة مفاعلة 4-هيدروكسي اسيتوفينون مع ايثيل ثيانو اسيتات

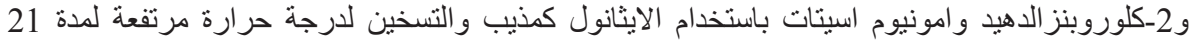

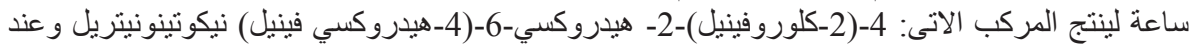

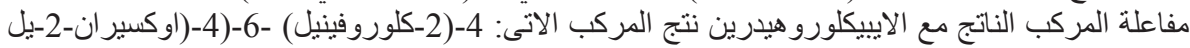

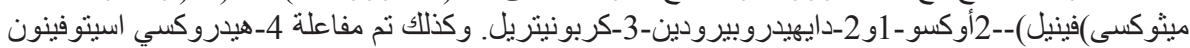

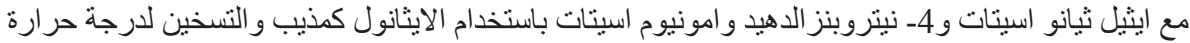

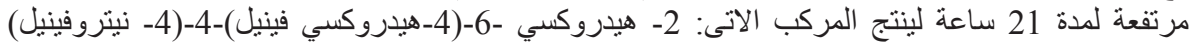

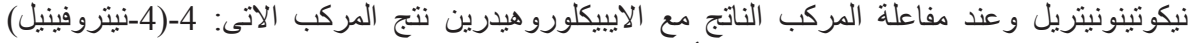

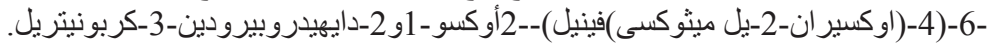

و كذلك تم اضافة المركبات الاربعة الذى تم تحضبر هم وكذلك اضافة الذنك برثيون كلا على حدا بنسبة

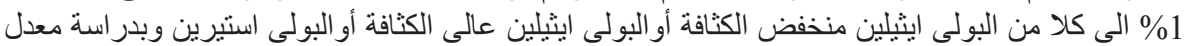

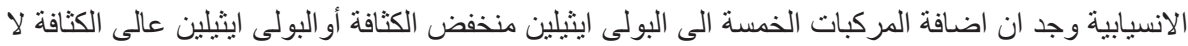

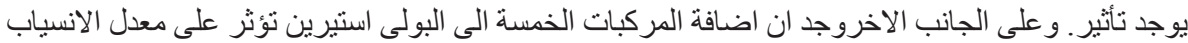

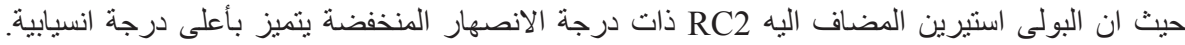

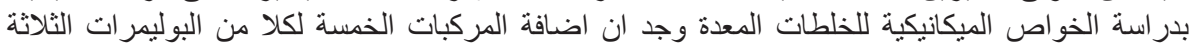

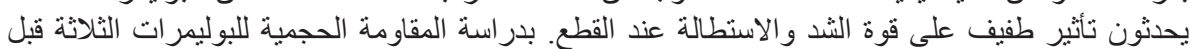

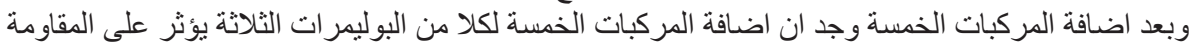

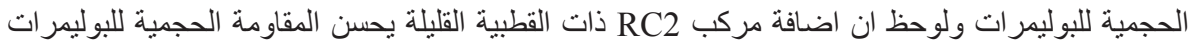

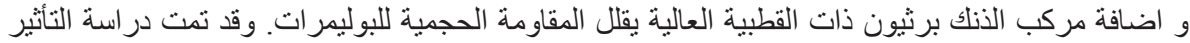

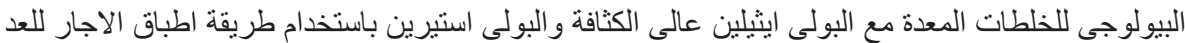

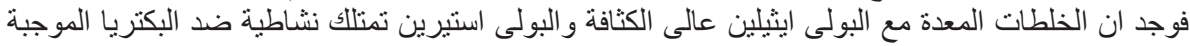

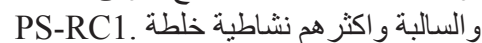

